\title{
Brain Reward Circuits in Morphine Addiction
}

\author{
Juhwan Kim ${ }^{1,2,4}$, Suji Ham ${ }^{1,2,3}$, Heeok Hong ${ }^{5}$, Changjong Moon ${ }^{4}$, and Heh-In $\operatorname{Im}^{1,2,3, *}$
}

\begin{abstract}
Morphine is the most potent analgesic for chronic pain, but its clinical use has been limited by the opiate's innate tendency to produce tolerance, severe withdrawal symptoms and rewarding properties with a high risk of relapse. To understand the addictive properties of morphine, past studies have focused on relevant molecular and cellular changes in the brain, highlighting the functional roles of reward-related brain regions. Given the accumulated findings, a recent, emerging trend in morphine research is that of examining the dynamics of neuronal interactions in brain reward circuits under the influence of morphine action. In this review, we highlight recent findings on the roles of several reward circuits involved in morphine addiction based on pharmacological, molecular and physiological evidences.
\end{abstract}

\section{INTRODUCTION}

Morphine is the first-line choice for the management of chronic, moderate-to-severe pain in both cancer and non-cancer patients (Clark, 2002; Gretton et al., 2013; Manchikanti et al., 2012; Schug et al., 1992; Schultheiss et al., 1992). Unfortunately, long-term treatment with morphine ultimately results in tolerance to morphine's analgesic effect (Mercadante, 1999; Trujillo and Akil, 1991), limiting its efficacy in clinical practice. A higher dose of morphine is often used to overcome tolerance, but this strategy exposes patients to a higher risk of developing severe side effects, such as morphine rewarding and withdrawal symptoms (Kumar et al., 2001; LeResche et al., 2015). Thus, there is a need to understand the molecular and functional mechanisms of morphine addiction to develop less addictive therapeutic substitutes for morphine. Recently, a number of studies have provided evidence for the complexity of anatomical and func-

\footnotetext{
${ }^{1}$ Center for Neuroscience, Brain Science Institute, ${ }^{2}$ Convergence Research Center for Diagnosis, Treatment and Care System of Dementia, Korea Institute of Science and Technology (KIST), Seoul 02792, Korea, ${ }^{3}$ Department of Neuroscience, Korea University of Science and Technology (UST), Daejeon 34113, Korea, ${ }^{4}$ Department of Veterinary Anatomy, College of Veterinary Medicine and Animal Medical Institute, Chonnam National University, Gwangju 61186, Korea, ${ }^{5}$ Department of Medical Science, Konkuk University School of Medicine, Seoul 05029, Korea ${ }^{*}$ Correspondence: him@kist.re.kr
}

Received 1 June, 2016; revised 18 July, 2016; accepted 20 July, 2016; published online 9 August, 2016

Keywords: addiction, morphine, opiate, reward circuits, withdrawal symptom tional interactions between neurons in brain reward circuits prompted by morphine's rewarding action (Fig. 1; Table 1). Here, we review the neuronal interactions in brain reward circuits under morphine reward.

\section{VENTRAL TEGMENTAL AREA (VTA)-NUCLEUS ACCUMBENS (NAC) CIRCUIT: DOPAMINERGIC (DA)/GAMMA-AMINOBUTYRIC ACID (GABA)ERGIC TRANSMISSION}

The mu-opioid receptor (MOR) is key to morphine's action, and there are several lines of evidence on the strong relationship between MOR activation in the ventral tegmental area (VTA) and reinforcing the effects of morphine. The VTA contains many MORs, and intra-VTA injection of a MOR antagonist significantly reduced morphine-induced conditioned place preference (CPP) (Mamoon et al., 1995; Olmstead and Franklin, 1997). Additionally, a behavioral study using delta-opioid-receptor (DOR) knockout mice and a DOR antagonist showed that DOR prevented the rewarding effects of morphine, suggesting that the action of DOR on morphine affects the nucleus accumbens (NAc) gamma-aminobutyric acid (GABA)ergic and VTA dopaminergic (DA) neurons (Chefer and Shippenberg, 2009). However, there is a report that the systemic injection of the kappaopioid receptor (KOR) does not alter the VTA DA release induced by DAMGO (Devine et al., 1993). Furthermore, several studies have shown the changes in dopamine receptors during morphine reward and withdrawal in VTA-NAc circuits (Chartoff et al., 2006; Muller and Unterwald, 2005).

For example, Chartoff et al. (2006) presented molecular evidence that a D1 receptor agonist significantly reduced MORantagonist-induced somatic withdrawal symptoms and increased GluR1 phosphorylation in the NAc of morphinedependent rats. Additionally, D1 dopamine and an N-methyl-daspartic acid (NMDA) glutamate receptor antagonist significantly reduced Fos protein, which systemic morphine up-regulated, in the NAc and substantia nigra (SN) (Bontempi and Sharp, 1997; Muller and Unterwald, 2005).

The VTA sends a dense pack of dopaminergic projections to the GABAergic medium spiny neurons (MSNs) in both the shell and core regions of the nucleus accumbens (Fig. 1; Table 1). Between the two sub-regions, dopaminergic transmission to the NAc shell is stimulated preferentially by morphine reward (Lecca et al., 2007; Pontieri et al., 1995). Specifically, it has been found that within VTA-NAc pathways, tyrosine hydroxylase $(\mathrm{TH})$, a well-known enzyme in the biosynthesis of dopamine (Daubner et al., 2011), is up-regulated level of TH expression in response to chronic morphine treatment indicates that up-regulated level of dopamine in the VTA-NAc circuits may 


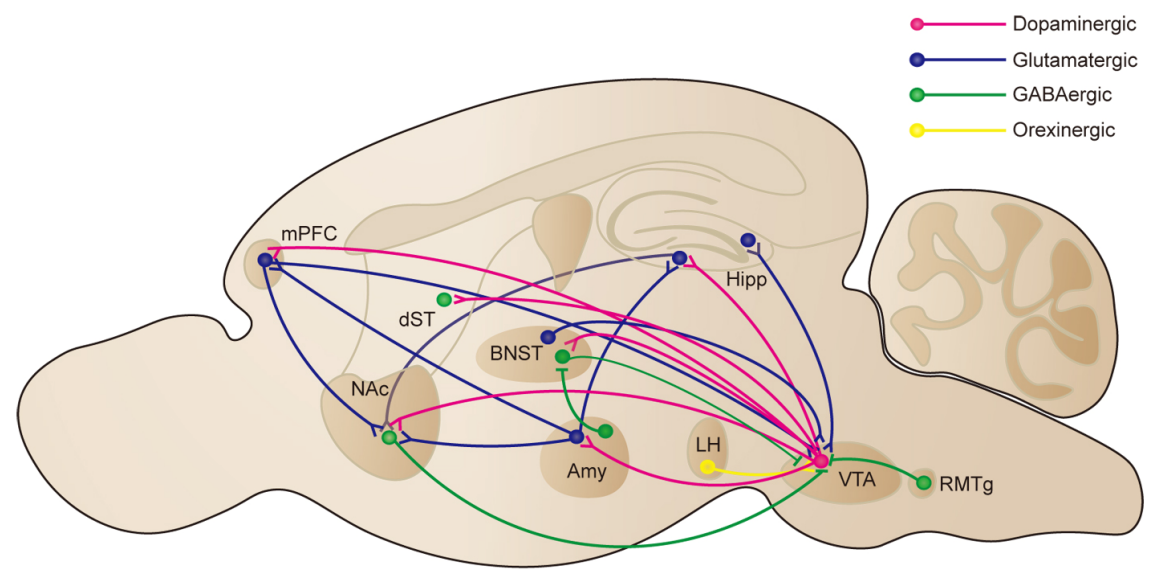

Fig. 1. Schematic diagram of brain reward circuits involved in morphine reward. The ventral tegmental area (VTA) projects dopaminergic (purple) transmission to the nucleus accumbens (NAc), medial prefrontal cortex (mPFC), hippocampus (Hipp), bed nucleus of the stria terminalis (BNST), amygdala (Amy), dorsal striatum (dST) and it modulates glutamatergic (blue) and gamma-aminobutyric acid (GABA) ergic (green) transmission. VTA dopaminergic (DA) neurons are also modulated by lateral hypothalamus (LH) orexinergic (yellow) neurons and rostromedial tegmental nucleus (RMTg) GABAergic neurons. Glutamatergic projections from the mPFC and Amy innervate the NAc to modulate NAc GABAergic transmission to the VTA, and glutamatergic transmission from the MPFC and BNST modulates VTA DA neurons.

play an important role in morphine and other opioid rewards (Beitner-Johnson and Nestler, 1991). Consistent with this, a study by Liang et al. (2012) confirmed dynamic changes in $\mathrm{TH}$ expression in VTA-NAc projection neurons by morphineinduced CPP in rats. Furthermore, acute treatment with morphine to rats followed by prolonged abstinence induces burst firing of VTA dopaminergic neurons, which are thought to play a role in encoding reward value (De Luca et al., 2011; Fields and Margolis, 2015; Jalabert et al., 2011; Schultz, 2002). A potential explanation for the increased burst firing rate of VTA dopaminergic neurons is reduced neuronal size. Chronic morphine treatment can reduce the size of VTA dopaminergic neurons, and smaller neurons are known to have lower membrane resistance, which could increase the overall neural firing rate in mice (Coque et al., 2011; Russo et al., 2007). Indeed, in vivo recording of mice brain has shown that chronic morphine treatment increased the basal firing rate and the burst firing rate in VTA dopaminergic neurons (Koo et al., 2012).

Dopaminergic transmission in VTA-NAc circuits can be modulated by effects of morphine treatment via cannabinoid and cholinergic systems (Cossu et al., 2001; Karimi et al., 2013; Khaleghzadeh-Ahangar and Haghparast, 2015; Melis et al., 2000; Rashidy-Pour et al., 2013; Rezayof et al., 2008). For example, Tanda et al. (1997) suggested that cannabinoids can activate VTA-NAc dopaminergic transmission by a common MOR-dependent mechanism shared with opioids, suggesting the possibility of crosstalk between cannabinoid and morphine signaling pathways. There is ultrastructural evidence that cannabinoid receptor type 1 (CB1)-labeled terminals interacted with $19 \%$ of the NAc shell and $13 \%$ of the NAc core containing MOR, and MOR-labeled terminals contacted $20 \%$ of the NAc shell and $10 \%$ of the NAc core containing CB1 receptors, suggesting the role of $\mathrm{CB} 1$ receptors in the rat NAc (Pickel et al., 2004). Indeed, intra-NAc injection of a CB1 receptor agonist can potentiate the rewarding effect of low-dose morphine and induce CPP, while a CB1 receptor antagonist inhibited morphine-induced CPP in rats (Karimi et al., 2013). Additionally, cholinergic inputs to the VTA can control morphine reward as well as morphine related-learning and locomotion by activating VTA dopaminergic neurons (Darbandi et al., 2008; Rezayof et al., 2007; 2008; Steidl and Yeomans, 2009). Morphine treatment induces a long-lasting increase in the cholinergic modula- tion of GABA synapses in the NAc, suggesting a modulatory role for cholinergic systems on the VTA-NAc dopaminergic system in adult rats (De Rover et al., 2005).

Along with dopaminergic efferents, the VTA receives GABAergic inputs from the rostromedial tegmental nucleus (RMTg) and the NAc (Fig. 1; Table 1). They are believed to modulate the activity of VTA dopaminergic neurons (Koo et al., 2012; Tan et al., 2012; Taylor et al., 2015; van Zessen et al., 2012). For example, during acute morphine treatment and withdrawal, VTA dopaminergic neurons are activated by disinhibition of GABAergic projections from the RMTg in rats (de Guglielmo et al., 2015; Kaufling and Aston-Jones, 2015; Lecca et al., 2012). Additionally, optogenetic stimulation of GABAergic inputs to VTA of mice brain can strongly inhibit the activity of VTA dopaminergic neurons and induce conditioned place aversion (Tan et al., 2012). However, it remains to be determined how GABAergic inputs on VTA dopaminergic neurons modulate morphine-dependent states.

Collectively, activation of dopaminergic neurons can potently modulate morphine reward. However, non-dopaminergic circuits also contribute to morphine reward (Miller et al., 2005; Neugebauer et al., 2013) but, currently, our knowledge of the non-dopaminergic circuits is limited. Understanding the contribution of VTA dopaminergic and non-dopaminergic circuits to morphine reward is important in future studies.

\section{VTA-AMYGDALA/ BED NUCLEUS OF THE STRIA TERMINALIS (BNST) CIRCUIT: DOPAMINERGICI GLUTAMATERGIC/GABAERGIC TRANSMISSION}

The amygdala is located in the medial temporal lobe and has 13 sub-regions, including the basolateral amygdala (BLA) and the central amygdala (CeA) (Amunts et al., 2005; Stamatakis et al., 2014). Several human studies have provided evidence for the role of the amygdala in drug-seeking behavior (Chase et al., 2011; Kufahl et al., 2005).

The BLA is thought to be a key region for reconsolidation of drug-related memory and reinstatement of drug-seeking behaviors (Fuchs et al., 2005; Kaufling and Aston-Jones, 2015). The VTA sends dopaminergic projections to the BLA and induces associative neuronal plasticity in the amygdala (Bissiere et al., 2003; Ford et al., 2006) (Fig. 1; Table 1). BLA-projecting VTA 
Table 1. Overview of the brain reward circuits in morphine reward

\begin{tabular}{|c|c|c|c|c|}
\hline Circuits & Tools & Phenotype & Projection type & References \\
\hline $\mathrm{RMTg} \rightarrow \mathrm{VTA}$ & $\begin{array}{l}\text { Antero/Retrograde tracer } \\
\text { Pharmacology }\end{array}$ & $\begin{array}{l}\text { Inactivation of RMTg reduces morphine- } \\
\text { induced increase of impulse activity of } \\
\text { VTA DA neurons }\end{array}$ & $\begin{array}{l}\text { GABAergic } \\
\text { transmission }\end{array}$ & $\begin{array}{l}\text { de Guglielmo et al. } \\
\qquad(2015)\end{array}$ \\
\hline $\mathrm{VTA} \rightarrow \mathrm{NAc}$ & Optogenetic stimulation & $\begin{array}{l}\text { Optical stimulation of VTA DA terminal in NAc } \\
\text { increases morphine-induced CPP }\end{array}$ & $\begin{array}{l}\text { Dopaminergic } \\
\text { transmission }\end{array}$ & Koo et al. (2012) \\
\hline \multirow[t]{2}{*}{$\mathrm{VTA} \rightarrow \mathrm{BLA}$} & $\begin{array}{l}\text { Retrograde tracer } \\
\text { ex vivo electrophysiology }\end{array}$ & $\begin{array}{l}\text { MOR agonist induces greater inhibition of } \\
\text { BLA-projecting neurons than NAc projecting } \\
\text { neurons }\end{array}$ & $\begin{array}{l}\text { Dopaminergic } \\
\text { transmission }\end{array}$ & Ford et al. (2006) \\
\hline & Pharmacology & $\begin{array}{l}\text { Intra-VTA morphine-induced CPP was } \\
\text { controlled by BLA Dopamine receptors }\end{array}$ & $\begin{array}{l}\text { Dopaminergic } \\
\text { transmission }\end{array}$ & Lintas et al. (2011) \\
\hline $\mathrm{BNST} \rightarrow \mathrm{VTA}$ & $\begin{array}{l}\text { Retrograde tracer } \\
\text { Electrophysiology }\end{array}$ & $\begin{array}{l}\text { Chronic morphine treatment up-regulated the } \\
\text { excitatory transmission in a subpopulation of } \\
\text { BNST neurons that project to the VTA }\end{array}$ & $\begin{array}{l}\text { Glutamatergic/ } \\
\text { GABAergic } \\
\text { transmission }\end{array}$ & Dumont et al. (2008) \\
\hline $\mathrm{CeA} \rightarrow \mathrm{BNST}$ & Pharmacology & $\begin{array}{l}\text { Inhibition of CeA GABA neurons reduced } \\
\text { morphine-induced CPP and reinstatement } \\
\text { with Fos expression in BNST }\end{array}$ & $\begin{array}{l}\text { GABAergic } \\
\text { transmission }\end{array}$ & Ma et al. (2008) \\
\hline $\mathrm{BLA} \rightarrow \mathrm{NAc}$ & Pharmacology & $\begin{array}{l}\text { Inhibition of NAc NMDA transmission blocks } \\
\text { potentiation of intra-BLA morphine-induced } \\
\text { CPP }\end{array}$ & $\begin{array}{l}\text { Glutamatergic } \\
\text { transmission }\end{array}$ & Lintas et al. (2012) \\
\hline $\mathrm{BLA} \rightarrow \mathrm{mPFC}$ & Pharmacology & $\begin{array}{l}\text { mPFC projecting BLA neurons control } \\
\text { morphine rewarding via CaMKII } \\
\text { signaling/NMDA signaling }\end{array}$ & $\begin{array}{l}\text { Glutamatergic } \\
\text { transmission }\end{array}$ & $\begin{array}{l}\text { Gholizadeh et al. } \\
\qquad \begin{array}{l}\text { (2013) } \\
\text { Rosen et al. (2015) }\end{array}\end{array}$ \\
\hline $\mathrm{VTA} \rightarrow \mathrm{mPFC}$ & $\begin{array}{l}\text { Retrograde tracer } \\
\text { Pharmacology }\end{array}$ & $\begin{array}{l}\text { Lesion of VTA DA terminal to mPFC blocks } \\
\text { infra-VTA MOR agonist induced CPP }\end{array}$ & $\begin{array}{l}\text { Dopaminergic } \\
\text { transmission }\end{array}$ & Narita et al. (2010) \\
\hline $\mathrm{mPFC} \rightarrow \mathrm{VTA}$ & Pharmacology & $\begin{array}{l}\text { Decreased glutamate transmission via NMDAR } \\
\text { and AMPAR enhances morphine-induced } \\
\text { CPP }\end{array}$ & $\begin{array}{l}\text { Glutamatergic } \\
\text { transmission }\end{array}$ & Bishop et al. (2011) \\
\hline $\mathrm{mPFC} \leftrightarrow \mathrm{VTA}$ & Pharmacology & $\begin{array}{l}\text { Inactivated CB1 receptors induce motivational } \\
\text { valence to morphine }\end{array}$ & $\begin{array}{l}\text { Cannabinoidergic } \\
\text { transmission }\end{array}$ & $\begin{array}{l}\text { De Jaeger et al. } \\
\qquad(2013) \\
\text { Ahmad et al. (2013) } \\
\text { Tan et al. (2014) }\end{array}$ \\
\hline $\mathrm{LH} \rightarrow \mathrm{VTA}$ & Pharmacology & $\begin{array}{l}\text { Intra-VTA orexin induces reinstatement of } \\
\text { morphine }\end{array}$ & $\begin{array}{l}\text { Orexinergic } \\
\text { transmission }\end{array}$ & Harris et al. (2005) \\
\hline VTA $\rightarrow$ Hipp & Pharmacology & $\begin{array}{l}\text { D1/D2 antagonist blocks acquisition of } \\
\text { morphine induced CPP }\end{array}$ & $\begin{array}{l}\text { Dopaminergic } \\
\text { transmission }\end{array}$ & Esmaeili et al. (2012) \\
\hline $\mathrm{VTA} \rightarrow \mathrm{dST}$ & Pharmacology & $\begin{array}{l}\text { MOR antagonist injection in the VTA blocked } \\
\text { Fos induction in the dST }\end{array}$ & $\begin{array}{l}\text { Dopaminergic } \\
\text { transmission }\end{array}$ & $\begin{array}{c}\text { Bontempi and Sharp } \\
(1997) \\
\end{array}$ \\
\hline
\end{tabular}

VTA, ventral tegmental area; NAc, nucleus accumbens; Hipp, hippocampus; BNST, bed nucleus of the stria terminalis; Amy, amygdala; dST, dorsal striatum; RMTg, rostromedial tegmental nucleus; $\mathrm{LH}$, lateral hypothalamus, mPFC, medial prefrontal cortex. CPP, conditioned place preference; CeA, central nucleus of the amygdala; BLA, basolateral amygdala; NMDA, N-methyl-D-aspartate receptor; CaMKII, Ca2+/calmodulin-dependent protein kinase II; AMPA, $\alpha$-amino-3-hydroxy-5-methyl-4-isoxazolepropionic acid. CB1, cannabinoid receptor type 1

neurons are regulated by opioid agonists independently from NAc-projecting VTA neurons, indicating that VTA dopaminergic neurons are heterogeneous and the opioid-induced behavioral effects may vary by specific changes in distinct subpopulations of dopaminergic neurons within the VTA (Ford et al., 2006). Similarly, Lintas et al. (2011) reported that blockade of dopa- mine D1 and D2 receptors in the BLA of Sprague Dawley (SD) rats can modulate intra-VTA morphine-induced CPP in both morphine-naïve and -dependent states.

The $\mathrm{CeA}$ sends out GABAergic projections that primarily control GABAergic drive in the bed nucleus of the stria terminalis (BNST), which receives dopaminergic inputs from the VTA 
(Dong et al., 2001; Li et al., 2012; Rezayof et al., 2009; Zarrindast et al., 2013) (Fig. 1; Table. 1). Intra-CeA injection of a D1 or D2 receptor agonist can induce morphine-induced CPP in rats (Rezayof et al., 2002; Zarrindast et al., 2003). In turn, chronic morphine treatment increases FosB expression in the CeA of rats, indicating initiation or maintaining of state of rewarding (Nestler, 2004; Nunez et al., 2010). Ma et al. (2008) also showed that inhibition of the $\mathrm{CeA}$ of rat brain reduced morphine-induced CPP and foot shock-induced CPP reinstatement with concurrent reduction of Fos expression in the BNST and the VTA, but Fos expression in the BNST was not altered by CeA modulation. Finnegan et al. (2006) examined that MOR activation on CeA-projecting GABAergic BLA neurons decreased GABAergic inputs to CeA via Kv1.1 and Kv1.2 signaling. Also, molecular and behavioral studies have shown the possible involvement of $\mathrm{CeA}$ in expression and reinstatement of morphine-induced CPP. Furthermore, Watanabe et al. (2003) suggested that non-dopaminergic systems, such as the noradrenergic system, also contribute to morphine rewarding in the $\mathrm{CeA}$. The BNST sends glutamatergic and GABAergic projections to the VTA (Jennings et al., 2013; Kudo et al., 2012; 2014; van Zessen et al., 2012). An early study provided electrophysiological evidence that chronic morphine can selectively increase $\alpha$-amino-3-hydroxy-5-methyl-4-isoxazole-propionic acid (AMPA)mediated excitatory postsynaptic currents in specific VTAprojecting BNST neurons of rats (Dumont et al., 2008). To support this result, more recent studies also found that optogenetic or pharmacological activation of GABAergic projections from the BNST to the VTA can inhibit VTA dopaminergic transmission (Jennings et al., 2013; van Zessen et al., 2012). Collectively, these findings indicate that amygdala subcircuits to the VTA may play important roles in modulating diverse components in morphine addiction.

\section{VTA-MEDIAL PREFRONTAL CORTEX (MPFC)/NAC CIRCUIT: DOPAMINERGIC/GLUTAMATERGIC TRANSMISSION}

The VTA sends dopaminergic projections to the mPFC, while the MPFC sends glutamatergic projections to both the VTA and the NAc (Peters and De Vries, 2012; Sesack and Carr, 2002) (Fig. 1; Table 1). Several studies have demonstrated that the VTA-mPFC circuit is involved in morphine reward. For example, intra-VTA infusion of a MOR agonist increased the dopamine level in the MPFC, and a decreased dopamine level in the mPFC can disrupt acquisition of mu-opioid agonist-induced CPP in rats (Narita et al., 2010). Furthermore, pharmacological blockade of either mPFC AMPA or NMDA receptors in the mPFC of rats increases morphine-induced CPP to its subthreshold dose and decreases dopamine release properties as changes of firing and bursting activities in VTA dopaminergic neurons (De Jaeger et al., 2013; Tan et al., 2014). However, either cellular or molecular contributions of altered glutamatergic transmission from the mPFC to VTA dopaminergic neurons in morphine addiction remains to be determined.

Another bidirectional circuit in the MPFC is the retrograde signaling of endocannabinoids from the VTA (Szabo et al., 2002). Cannabinoid transmission through CB1 receptor in mPFC is known to modulate emotional processing, memory, and balance of morphine-related reward and aversion in rats (Ahmad et al., 2013; Milad and Quirk, 2002). According to Ahmad et al. (2013), activation of CB1 transmission induces aversion to morphine, whereas inhibition of CB1 transmission produces motivation towards morphine. This bidirectional control of morphine preference could be interpreted with the mPFC-VTA circuit. Low activation of CB1 receptors in the mPFC is known to increase the spontaneous firing of VTA dopaminergic neurons, whereas high activation inhibits spontaneous dopaminergic neuron activity (Ahmad et al., 2013). The major modulatory signaling in the MPFC-VTA circuit for morphine reward may be inhibitory, because CB1 receptors in the MPFC can control VTA dopaminergic transmission through GABAergic signaling (Dacher and Nugent, 2011; Dazzi et al., 2014). Together, these studies suggest that CB1 transmission from the mPFC plays a prominent role in emotional processing for morphine through the modulation of VTA dopaminergic neurons.

\section{VTA-HIPPOCAMPUS CIRCUIT: DOPAMINERGICI GLUTAMATERGIC TRANSMISSION}

According to Lisman and Grace (2005), the hippocampus-VTA circuit consists of bidirectional pathways. The first pathway involves dopaminergic projections from the VTA to the hippocampus (Fig. 1; Table 1). Dopamine transmission can induce long-term potentiation (LTP) in the hippocampus when presented with novel stimuli in rodents (Gasbarri et al., 1997; Lisman and Grace, 2005; Schott et al., 2004). Accordingly, the role of the VTA-hippocampus circuit in rewards could be involved in, and may be restricted to, the acquisition of novel rewarding stimuli in the fMRI study using human brain (Bunzeck et al., 2012). Recent studies in morphine reward also showed a role for the VTA-hippocampus in the acquisition of morphineinduced CPP. For example, administering an antagonist of D1 or D2 receptors in the hippocampal CA1 can inhibit the acquisition of intra-VTA morphine-induced CPP in rats (Esmaeili et al., 2012; Haghparast et al., 2013). The second pathway is from the hippocampus to the VTA, which is activated when the hippocampus detects a previously learned rewarding cue (Lisman and Grace, 2005) and plays a role in spatial reinforcement learning (Keleta and Martinez, 2012). This circuit is also intermingled with other brain regions. Specifically, hippocampal CA3 glutamatergic neurons can activate GABAergic neurons of the caudodorsal lateral septum and the NAc, which, in turn, increase dopamine releases in the VTA by the disinhibition of GABAergic projections to the VTA (Luo et al., 2011). Together, these studies suggest a relationship between morphine reward and the hippocampus-VTA circuit.

\section{AMYGDALA-NAC/HIPPOCAMPUS/MPFC CIRCUIT: GLUTAMATERGIC TRANSMISSION}

The BLA sends glutamatergic projections to NAc GABAergic neurons, and neurotransmission within BLA-NAc circuit is involved in reward-seeking behavior (Ambroggi et al., 2008; Everitt et al., 1999; Stamatakis et al., 2014) (Fig. 1; Table 1). Specifically, BLA projections to NAc neurons are necessary for cue-evoked excitation of NAc neurons, through which the excited NAc neurons promote reward-seeking behavior (Ambroggi et al., 2008). Additionally, BLA efferents to the NAc shell can control opiate reward via differential regulation of D1 or D2 receptor signaling in rats (Lintas et al., 2012).

The BLA also sends glutamatergic projections to the hippocampus (Rei et al., 2015), and the synaptic plasticity induced by BLA-hippocampus glutamatergic transmission mediates the formation of learning and memory required for opioid addiction (Eisch et al., 2000; Han et al., 2015; Lu et al., 2010; Pu et al., 2002). Also, cannabinoids are involved in hippocampal rewardrelated learning by modulating glutamatergic transmission in 
rodents (Polissidis et al., 2013; Zarrindast et al., 2007). However, the neuronal interplay between the BLA and the hippocampus still needs to be clarified in the context of morphine reward. The mPFC receives glutamatergic inputs from the BLA, and this circuit plays a role in memory consolidation (Yu et al., 2012). The mPFC is known to be related to the formation of associative memory between morphine and non-salient cues, and relapse in morphine addiction in rodents animal models (De Jaeger et al., 2013; Li et al., 2008; Ventura et al., 2005). Furthermore, the mPFC is believed to be important for processing salient information that drives conditioned behavioral responses (Quirk and Mueller, 2008; Stamatakis et al., 2014). Consistent with this, Gholizadeh et al. (2013) revealed that protein synthesis in the BLA controls the consolidation of morphine-related memory in $\mathrm{mPFC}$ via calcium/calmodulin-dependent protein kinase II (CaMKII) signaling. Additionally, a morphine-related memory switch is controlled by D2 receptor-CaMKII signaling within the BLA-mPFC circuit in rats (Rosen et al., 2015). Specifically, blockade of NMDA receptors in the prelimbic subdivision of the mPFC of rats can strongly potentiate the rewarding effects of systemic and intra-VTA morphine treatment, but inactivation of the BLA blocks this behavioral potentiation (Bishop et al., 2011). Together, these data suggest that chronic morphine treatment induces excitatory synaptic drive in the BLA-NAc circuit that is strongly involved in morphine addiction, and demonstrate that the BLA-mPFC circuit plays an important role in drug-related cue learning.

\section{LATERAL HYPOTHALAMUS (LH)-VTA CIRCUIT: OREXINERGIC TRANSMISSION}

Hypothalamus neurons in the brain are known to exclusively produce orexin neuropeptides that bind to orexin-1 or orexin-2 receptors (de Lecea et al., 1998; Sakurai et al., 1998). The hypothalamus consists of small sub-regions, and each has varied and segregated functions (Merkle et al., 2015). Among the sub-regions, the lateral hypothalamus $(\mathrm{LH})$ is considered to play a role in reward-related behavior (Cason et al., 2010; Cazala et al., 1987; Richardson and Aston-Jones, 2012).

Fifty percent of LH neurons are orexinergic neurons (Georgescu et al., 2003), while the other $50 \%$ consists of various other neuropeptidergic neurons, including glucagon-like peptide-1, oxytocin, and arginine-vasopressin neurons (de Lecea et al., 1998; Merkle et al., 2015). The transmission from LH orexinergic neurons to VTA dopaminergic neurons is mediated by the orexin-1 receptors (Razavi et al., 2014). LH orexinergic neurons have a role in rewarding, withdrawal, and synaptic plasticity induced by morphine (Baimel and Borgland, 2015; Georgescu et al., 2003). For example, withdrawal after treatment with an escalating dose of morphine for 10 days caused the up-regulation of MOR and orexin mRNA in the LH, as well as the striatum (Zhou et al., 2006). In addition, Georgescu et al. (2003) reported that MOR on LH orexinergic neurons induced CAMP response element-binding protein (CREB) and c-Fos expression during chronic morphine exposure and withdrawal using orexin knockout mice. Furthermore, LH orexin knockout mice show reduced both rewarding and withdrawal responses (Georgescu et al., 2003).

The circuitry between the LH and VTA could indirectly or directly control rewarding effects of morphine (Baimel and Borgland, 2015; Harris et al., 2005) (Fig. 1; Table 1). Specifically, activation of $\mathrm{LH}$ orexinergic neurons by rat pancreatic polypeptide or intra-VTA injection of orexin can reinstate previously extinguished morphine-induced CPP in rats (Harris et al., 2005).
Furthermore, morphine exposure-mediated modulation of the orexin-1 receptors in VTA dopaminergic neurons can increase presynaptic glutamate releases and decrease GABA releases, supporting the idea that LH orexinergic projections to VTA dopaminergic neurons play a modulatory role in morphine reward (Baimel and Borgland, 2015).

\section{DORSAL STRIATUM (DST)}

The role of the dorsal striatum (dST) in addiction is important in the development of habitual and compulsive drug use (Everitt and Robbins, 2013; Koob and Volkow, 2010). Especially within the dST, the dorsomedial striatum is more closely related to acquisition and drug seeking than the dorsolateral striatum (Everitt, 2014). Nguyen et al. (2014) reported that injection of a transient receptor potential vanilloid type 1 (TRPV1) antagonist into the dST inhibited morphine-induced MOR interaction proteins, such as adenylyl cyclase 1 (AC), p38 mitogen-activated protein kinase (p38 MAPK), and nuclear factor kappa B (NF$\kappa B)$, suggesting the important role of MOR in the dST.

Moreover, many studies stressed that the dST and the NAc shell play roles in morphine-seeking behavior induced by drugassociated cues (Bontempi and Sharp, 1997; Gao et al., 2013; Guo et al., 2008; Suto et al., 2011). More specifically, morphineinduced MOR activation in the SN and the VTA leads to Fos expression within the dST of rats, suggesting dST function is controlled by dST projecting VTA dopaminergic neurons (Bontempi and Sharp, 1997) (Fig. 1; Table 1). Additionally, chronic morphine can decrease expression of the delta-opioid receptor in the cholinergic interneurons of the dorsolateral striatum (Leah et al., 2015). A recent study by Ziolkowska et al. (2015) reported that morphine induced two distinct episodes of immediate early gene induction in the dST, where the first was related to the dST-NAc shell circuits and the subsequent expression was related to the dST-cortex circuits in mice (Ziolkowska et al., 2015). These studies suggest a role for the dST in morphine reward.

\section{CONCLUSION}

Brain reward circuitry studies have provided an improved mechanistic understanding of morphine addiction. Specifically, clarifying the causal relationship within reward circuitry has served to further interpret morphine-specific functional and molecular changes in multiple reward-related brain regions. Various changes are reflected in the distinct connectivity and function of brain reward circuits. In this era, advances in sophisticated imaging, tracing, and genetic and optogenetic tools make it possible to analyze the complex neural networks underlying the morphine-specific brain reward circuits. With these new tools, future studies should focus on identifying the exact afferents and efferents modulated under specific symptoms of morphine reward, which may provide novel pharmacological targets for the treatment of morphine addiction.

\section{ACKNOWLEDGMENTS}

This work was supported by the National Research Council of Science \& Technology (NST) grant by the Korea government (MSIP) (No. CRC-15-04-KIST).

\section{REFERENCES}

Ahmad, T., Lauzon, N.M., de Jaeger, X., and Laviolette, S.R. (2013). Cannabinoid transmission in the prelimbic cortex bidirectionally controls opiate reward and aversion signaling 
through dissociable kappa versus mu-opiate receptor dependent mechanisms. J. Neurosci. 33, 15642-15651.

Ambroggi, F., Ishikawa, A., Fields, H.L. , and Nicola, S.M. (2008). Basolateral amygdala neurons facilitate reward-seeking behavior by exciting nucleus accumbens neurons. Neuron 59, 648-661.

Amunts, K., Kedo, O., Kindler, M., Pieperhoff, P., Mohlberg, H., Shah, N.J., Habel, U., Schneider, F., and Zilles, K. (2005). Cytoarchitectonic mapping of the human amygdala, hippocampal region and entorhinal cortex: intersubject variability and probability maps. Anat. Embryol. (Berl.) 210, 343-352.

Baimel, C., and Borgland, S.L. (2015). Orexin signaling in the VTA gates morphine-induced synaptic plasticity. J. Neurosci. 35, 7295-7303.

Beitner-Johnson, D., and Nestler, E.J. (1991). Morphine and cocaine exert common chronic actions on tyrosine hydroxylase in dopaminergic brain reward regions. J. Neurochem. 57, 344-347.

Bishop, S.F., Lauzon, N.M., Bechard, M., Gholizadeh, S., and Laviolette, S.R. (2011). NMDA receptor hypofunction in the prelimbic cortex increases sensitivity to the rewarding properties of opiates via dopaminergic and amygdalar substrates. Cereb. Cortex 21, 68-80.

Bissiere, S., Humeau, Y., and Luthi, A. (2003). Dopamine gates LTP induction in lateral amygdala by suppressing feedforward inhibition. Nat. Neurosci. 6, 587-592.

Bontempi, B., and Sharp, F.R. (1997). Systemic morphine-induced Fos protein in the rat striatum and nucleus accumbens is regulated by mu opioid receptors in the substantia nigra and ventral tegmental area. J. Neurosci. 17, 8596-8612.

Bunzeck, N., Doeller, C.F., Dolan, R.J., and Duzel, E. (2012). Contextual interaction between novelty and reward processing within the mesolimbic system. Hum. Brain Mapp. 33, 1309-1324.

Cason, A.M., Smith, R.J., Tahsili-Fahadan, P., Moorman, D.E., Sartor, G.C., and Aston-Jones, G. (2010). Role of orexin/hypocretin in reward-seeking and addiction: implications for obesity. Physiol. Behav. 100, 419-428.

Cazala, P., Darracq, C., and Saint-Marc, M. (1987). Selfadministration of morphine into the lateral hypothalamus in the mouse. Brain Res. 416, 283-288.

Chartoff, E.H., Mague, S.D., Barhight, M.F., Smith, A.M., and Carlezon, W.A., Jr. (2006). Behavioral and molecular effects of dopamine D1 receptor stimulation during naloxone-precipitated morphine withdrawal. J. Neurosci. 26, 6450-6457.

Chase, H.W., Eickhoff, S.B., Laird, A.R., and Hogarth, L. (2011). The neural basis of drug stimulus processing and craving: an activation likelihood estimation meta-analysis. Biol. Psychiatry 70, 785-793.

Chefer, V.I., and Shippenberg, T.S. (2009). Augmentation of morphine-induced sensitization but reduction in morphine tolerance and reward in delta-opioid receptor knockout mice. Neuropsychopharmacology 34, 887-898.

Clark, J.D. (2002). Chronic pain prevalence and analgesic prescribing in a general medical population. J. Pain Symptom Manage. 23, 131-137.

Coque, L., Mukherjee, S., Cao, J.L., Spencer, S., Marvin, M., Falcon, E., Sidor, M.M., Birnbaum, S.G., Graham, A., Neve, R.L., et al. (2011). Specific role of VTA dopamine neuronal firing rates and morphology in the reversal of anxiety-related, but not depression-related behavior in the ClockDelta19 mouse model of mania. Neuropsychopharmacology 36, 1478-1488.

Cossu, G., Ledent, C., Fattore, L., Imperato, A., Bohme, G.A., Parmentier, M., and Fratta, W. (2001). Cannabinoid CB1 receptor knockout mice fail to self-administer morphine but not other drugs of abuse. Behav. Brain Res. 118, 61-65.

Dacher, M., and Nugent, F.S. (2011). Morphine-induced modulation of LTD at GABAergic synapses in the ventral tegmental area. Neuropharmacology 61, 1166-1171.

Darbandi, N., Rezayof, A., and Zarrindast, M.R. (2008). Modulation of morphine state-dependent learning by muscarinic cholinergic receptors of the ventral tegmental area. Physiol. Behav. 94, 604610.

Daubner, S.C., Le, T., and Wang, S. (2011). Tyrosine hydroxylase and regulation of dopamine synthesis. Arch. Biochem. Biophys. 508, 1-12

Dazzi, L., Talani, G., Biggio, F., Utzeri, C., Lallai, V., Licheri, V., Lutzu, S., Mostallino, M.C., Secci, P.P., Biggio, G., et al. (2014). Involvement of the cannabinoid CB1 receptor in modulation of dopamine output in the prefrontal cortex associated with food restriction in rats. PLoS One 9, e92224.

de Guglielmo, G., Melis, M., De Luca, M.A., Kallupi, M., Li, H.W., Niswender, K., Giordano, A., Senzacqua, M., Somaini, L., Cippitelli, A., et al. (2015). PPARgamma activation attenuates opioid consumption and modulates mesolimbic dopamine transmission. Neuropsychopharmacology 40, 927-937.

De Jaeger, X., Bishop, S.F., Ahmad, T., Lyons, D., Ng, G.A., and Laviolette, S.R. (2013). The effects of AMPA receptor blockade in the prelimbic cortex on systemic and ventral tegmental area opiate reward sensitivity. Psychopharmacology (Berl.) 225, 687695.

de Lecea, L., Kilduff, T.S., Peyron, C., Gao, X., Foye, P.E., Danielson, P.E., Fukuhara, C., Battenberg, E.L., Gautvik, V.T., Bartlett, F.S., 2nd, et al. (1998). The hypocretins: hypothalamusspecific peptides with neuroexcitatory activity. Proc. Natl. Acad. Sci. USA 95, 322-327.

De Luca, M.A., Bimpisidis, Z., Bassareo, V., and Di Chiara, G. (2011). Influence of morphine sensitization on the responsiveness of mesolimbic and mesocortical dopamine transmission to appetitive and aversive gustatory stimuli. Psychopharmacology (Berl.). 216, 345-353.

De Rover, M., Lodder, J.C., Schoffelmeer, A.N., and Brussaard, A.B. (2005). Intermittent morphine treatment induces a longlasting increase in cholinergic modulation of GABAergic synapses in nucleus accumbens of adult rats. Synapse 55, 17-25

Devine, D.P., Leone, P., Pocock, D., and Wise, R.A. (1993). Differential involvement of ventral tegmental mu, delta and kappa opioid receptors in modulation of basal mesolimbic dopamine release: in vivo microdialysis studies. J. Pharmacol. Exp. Ther. 266, 1236-1246.

Dong, H.W., Petrovich, G.D., Watts, A.G., and Swanson, L.W. (2001). Basic organization of projections from the oval and fusiform nuclei of the bed nuclei of the stria terminalis in adult rat brain. J. Comp. Neurol. 436, 430-455.

Dumont, E.C., Rycroft, B.K., Maiz, J., and Williams, J.T. (2008). Morphine produces circuit-specific neuroplasticity in the bed nucleus of the stria terminalis. Neuroscience 153, 232-239.

Eisch, A.J., Barrot, M., Schad, C.A., Self, D.W., and Nestler, E.J. (2000). Opiates inhibit neurogenesis in the adult rat hippocampus. Proc. Natl. Acad. Sci. USA 97, 7579-7584.

Esmaeili, M.H., Kermani, M., Parvishan, A., and Haghparast, A. (2012). Role of D1/D2 dopamine receptors in the CA1 region of the rat hippocampus in the rewarding effects of morphine administered into the ventral tegmental area. Behav. Brain Res. 231, 111-115.

Everitt, B.J. (2014). Neural and psychological mechanisms underlying compulsive drug seeking habits and drug memories-indications for novel treatments of addiction. Eur. J. Neurosci. 40, 2163-2182.

Everitt, B.J., Parkinson, J.A., Olmstead, M.C., Arroyo, M., Robledo, P., and Robbins, T.W. (1999). Associative processes in addiction and reward. The role of amygdala-ventral striatal subsystems. Ann. N Y Acad. Sci. 877, 412-438.

Everitt, B.J., and Robbins, T.W. (2013). From the ventral to the dorsal striatum: devolving views of their roles in drug addiction. Neurosci. Biobehav. Rev. 37, 1946-1954.

Fields, H.L., and Margolis, E.B. (2015). Understanding opioid reward. Trends Neurosci. 38, 217-225.

Finnegan, T.F., Chen, S.R., and Pan, H.L. (2006). Mu opioid receptor activation inhibits GABAergic inputs to basolateral amygdala neurons through Kv1.1/1.2 channels. J. Neurophysiol. 95, 2032-2041.

Ford, C.P., Mark, G.P., and Williams, J.T. (2006). Properties and opioid inhibition of mesolimbic dopamine neurons vary according to target location. J. Neurosci. 26, 2788-2797.

Fuchs, R.A., Evans, K.A., Ledford, C.C., Parker, M.P., Case, J.M., Mehta, R.H., and See, R.E. (2005). The role of the dorsomedial prefrontal cortex, basolateral amygdala, and dorsal hippocampus in contextual reinstatement of cocaine seeking in rats. Neuropsychopharmacology 30, 296-309.

Gao, J., Li Y., Zhu, N., Brimijoin, S., and Sui, N. (2013). Roles of dopaminergic innervation of nucleus accumbens shell and dorsolateral caudate-putamen in cue-induced morphine seeking after prolonged abstinence and the underlying D1- and D2-like receptor mechanisms in rats. J. Psychopharmacol. 27, 181-191. 
Gasbarri, A., Sulli, A., and Packard, M.G. (1997). The dopaminergic mesencephalic projections to the hippocampal formation in the rat. Prog. Neuropsychopharmacol. Biol. Psychiatry 21, 1-22.

Georgescu, D., Zachariou, V., Barrot, M., Mieda, M., Willie, J.T., Eisch, A.J., Yanagisawa, M., Nestler E.J., and DiLeone R.J. (2003). Involvement of the lateral hypothalamic peptide orexin in morphine dependence and withdrawal. J. Neurosci. 23, 31063111.

Gholizadeh, S., Sun, N., De Jaeger, X., Bechard, M., Coolen, L., and Laviolette, S.R. (2013). Early versus late-phase consolidation of opiate reward memories requires distinct molecular and temporal mechanisms in the amygdala-prefrontal cortical pathway. PLoS One 8, e63612.

Gretton, S.K., Ross, J.R., Rutter, D., Sato, H., Droney, J.M., Welsh, K.I., Joel, S., and Riley, J. (2013). Plasma morphine and metabolite concentrations are associated with clinical effects of morphine in cancer patients. J. Pain Symptom Manage. 45, 670680.

Guo, N., Garcia, M.M., and Harlan, R.E. (2008). A morphine-paired environment alters c-Fos expression in the forebrain of rats displaying conditioned place preference or aversion. Behav. Neurosci. 122, 1078-1086.

Haghparast, A., Esmaeili, M.H., Taslimi, Z., Kermani, M., YazdiRavandi, S., and Alizadeh, A.M. (2013). Intrahippocampal administration of D2 but not D1 dopamine receptor antagonist suppresses the expression of conditioned place preference induced by morphine in the ventral tegmental area. Neurosci. Lett. 541, 138-143.

Han, H., Dong, Z., Jia, Y., Mao, R., Zhou, Q., Yang, Y., Wang, L., $\mathrm{Xu}$, L., and Cao, J. (2015). Opioid addiction and withdrawal differentially drive long-term depression of inhibitory synaptic transmission in the hippocampus. Sci. Rep. 5, 9666.

Harris, G.C., Wimmer, M., and Aston-Jones, G. (2005). A role for lateral hypothalamic orexin neurons in reward seeking. Nature 437, 556-559.

Jalabert, M., Bourdy, R., Courtin, J., Veinante, P., Manzoni, O.J., Barrot, M., and Georges, F. (2011). Neuronal circuits underlying acute morphine action on dopamine neurons. Proc. Natl. Acad. Sci. USA 108, 16446-16450

Jennings, J.H., Sparta, D.R., Stamatakis, A.M., Ung, R.L., Pleil, K.E., Kash, T.L., and Stuber, G.D. (2013). Distinct extended amygdala circuits for divergent motivational states. Nature 496, 224-228.

Karimi, S., Azizi, P., Shamsizadeh, A., and Haghparast, A. (2013). Role of intra-accumbal cannabinoid CB1 receptors in the potentiation, acquisition and expression of morphine-induced conditioned place preference. Behav. Brain Res. 247, 125-131.

Kaufling, J., and Aston-Jones, G. (2015). Persistent adaptations in afferents to ventral tegmental dopamine neurons after opiate withdrawal. J. Neurosci. 35, 10290-10303.

Keleta, Y.B., and Martinez, J.L. (2012). Brain Circuits of Methamphetamine Place Reinforcement Learning: The Role of the Hippocampus-VTA Loop. Brain Behav 2, 128-141.

Khaleghzadeh-Ahangar, H., and Haghparast, A. (2015). Intraaccumbal CB1 receptor blockade reduced extinction and reinstatement of morphine. Physiol. Behav. 149, 212-219.

Koo, J.W., Mazei-Robison, M.S., Chaudhury, D., Juarez, B., LaPlant, Q., Ferguson, D., Feng, J., Sun H., Scobie, K.N., Damez-Werno, D., et al. (2012). BDNF is a negative modulator of morphine action. Science 338, 124-128.

Koob, G.F., and Volkow, N.D. (2010). Neurocircuitry of addiction. Neuropsychopharmacology 35, 217-238.

Kudo, T., Uchigashima, M., Miyazaki, T., Konno, K., Yamasaki, M., Yanagawa, Y., Minami, M., and Watanabe, M. (2012). Three types of neurochemical projection from the bed nucleus of the stria terminalis to the ventral tegmental area in adult mice. $\mathrm{J}$. Neurosci. 32, 18035-18046.

Kudo, T., Konno, K., Uchigashima, M., Yanagawa, Y., Sora, I., Minami, M., and Watanabe, M. (2014). GABAergic neurons in the ventral tegmental area receive dual GABA/enkephalinmediated inhibitory inputs from the bed nucleus of the stria terminalis. Eur. J. Neurosci. 39, 1796-1809.

Kufahl, P.R., Li, Z., Risinger, R.C., Rainey, C.J., Wu, G., Bloom, A.S., and Li, S.J. (2005). Neural responses to acute cocaine administration in the human brain detected by fMRI. Neuroimage $28,904-914$
Kumar, K., Kelly, M., and Pirlot, T. (2001). Continuous intrathecal morphine treatment for chronic pain of nonmalignant etiology: long-term benefits and efficacy. Surg. Neurol. 55, 79-86; discussion 86-78.

Leah, P.M., Heath, E.M., Balleine, B.W., and Christie, M.J. (2015). Chronic morphine reduces surface expression of delta-opioid receptors in subregions of rostral striatum. Neurochem. Res. 41, 500-509.

Lecca, D., Valentini, V., Cacciapaglia, F., Acquas, E., and Di Chiara, G. (2007). Reciprocal effects of response contingent and noncontingent intravenous heroin on in vivo nucleus accumbens shell versus core dopamine in the rat: a repeated sampling microdialysis study. Psychopharmacology (Berl.) 194, 103-116.

Lecca, S., Melis, M., Luchicchi, A., Muntoni, A.L., and Pistis, M. (2012). Inhibitory inputs from rostromedial tegmental neurons regulate spontaneous activity of midbrain dopamine cells and their responses to drugs of abuse. Neuropsychopharmacology 37, 1164-1176.

LeResche, L., Saunders, K., Dublin, S., Thielke, S., Merrill, J.O., Shortreed, S.M., Campbell, C., and Von Korff, M.R. (2015). Sex and age differences in global pain status among patients using opioids long term for chronic noncancer pain. J. Womens Health (Larchmt). 24, 629-635.

Li, T., Yan, C.X., Hou, Y., Cao, W., Chen, T., Zhu, B.F., and Li, S.B. (2008). Cue-elicited drug craving represses ERK activation in mice prefrontal association cortex. Neurosci. Lett. 448, 99-104.

Li, C., Pleil, K.E., Stamatakis, A.M., Busan, S., Vong, L., Lowell, B.B., Stuber, G.D., and Kash, T.L. (2012). Presynaptic inhibition of gamma-aminobutyric acid release in the bed nucleus of the stria terminalis by kappa opioid receptor signaling. Biol. Psychiatry 71, 725-732.

Liang, J., Ma, S.S., Li, Y.J., Ping, X.J., Hu, L., and Cui, C.L. (2012). Dynamic changes of tyrosine hydroxylase and dopamine concentrations in the ventral tegmental area-nucleus accumbens projection during the expression of morphine-induced conditioned place preference in rats. Neurochem. Res. 37, 14821489.

Lintas, A., Chi, N., Lauzon, N.M., Bishop, S.F., Gholizadeh, S., Sun, N., Tan, H., and Laviolette, S.R. (2011). Identification of a dopamine receptor-mediated opiate reward memory switch in the basolateral amygdala-nucleus accumbens circuit. J. Neurosci. 31 $11172-11183$.

Lintas, A., Chi, N., Lauzon, N.M., Bishop, S.F., Sun, N., Tan, H. and Laviolette, S.R. (2012). Inputs from the basolateral amygdala to the nucleus accumbens shell control opiate reward magnitude via differential dopamine D1 or D2 receptor transmission. Eur. J. Neurosci. 35, 279-290.

Lisman, J.E., and Grace, A.A. (2005). The hippocampal-VTA loop: controlling the entry of information into long-term memory. Neuron 46, 703-713.

Lu, G., Zhou, Q.X., Kang, S., Li, Q.L., Zhao, L.C., Chen, J.D., Sun, J.F., Cao, J., Wang, Y.J., Chen, J., et al. (2010). Chronic morphine treatment impaired hippocampal long-term potentiation and spatial memory via accumulation of extracellular adenosine acting on adenosine A1 receptors. J. Neurosci. 30, 5058-5070.

Luo, A.H., Tahsili-Fahadan, P., Wise, R.A., Lupica, C.R., and Aston-Jones, G. (2011). Linking context with reward: a functional circuit from hippocampal CA3 to ventral tegmental area. Science 333, 353-357.

Ma, D.Y., Xu, M.Y., Yang, H.C., and Yang, L.Z. (2008). Effect of inhibition of the central nucleus of the amygdala and drug experience on the regions underlying footshock-induced reinstatement of morphine seeking. J. Int. Med. Res. 36, 9921000.

Mamoon, A.M., Barnes, A.M., Ho, I.K., and Hoskins, B. (1995). Comparative rewarding properties of morphine and butorphanol. Brain Res. Bull. 38, 507-511.

Manchikanti, L., Abdi, S., Atluri, S., Balog, C.C., Benyamin, R.M., Boswell, M.V., Brown, K.R., Bruel, B.M., Bryce, D.A., Burks, P.A., et al. (2012). American Society of Interventional Pain Physicians (ASIPP). guidelines for responsible opioid prescribing in chronic non-cancer pain: Part I--evidence assessment. Pain Physician 15, S1-65.

Melis, M., Gessa, G.L., and Diana, M. (2000). Different mechanisms for dopaminergic excitation induced by opiates and cannabinoids in the rat midbrain. Prog. Neuropsychopharmacol. Biol. Psychiatry 
24, 993-1006.

Mercadante, S. (1999). Problems of long-term spinal opioid treatment in advanced cancer patients. Pain 79, 1-13.

Merkle, F.T., Maroof, A., Wataya, T., Sasai, Y., Studer, L., Eggan, K., and Schier, A.F. (2015). Generation of neuropeptidergic hypothalamic neurons from human pluripotent stem cells. Development 142, 633-643.

Milad, M.R., and Quirk, G.J. (2002). Neurons in medial prefrontal cortex signal memory for fear extinction. Nature 420, 70-74.

Miller, A.D., Forster, G.L., Yeomans, J.S., and Blaha, C.D. (2005) Midbrain muscarinic receptors modulate morphine-induced accumbal and striatal dopamine efflux in the rat. Neuroscience $136,531-538$

Muller, D.L., and Unterwald, E.M. (2005). D1 dopamine receptors modulate deltaFosB induction in rat striatum after intermittent morphine administration. J. Pharmacol. Exp. Ther. 314, 148-154.

Narita, M., Matsushima, Y., Niikura, K., Narita, M., Takagi, S., Nakahara, K., Kurahashi, K., Abe, M., Saeki, M., Asato, M., et al. (2010). Implication of dopaminergic projection from the ventral tegmental area to the anterior cingulate cortex in mu-opioidinduced place preference. Addict. Biol. 15, 434-447.

Nestler, E.J. (2004). Historical review: Molecular and cellular mechanisms of opiate and cocaine addiction. Trends Pharmacol. Sci. 25, 210-218.

Neugebauer, N.M., Einstein, E.B., Lopez, M.B., McClure-Begley, T.D., Mineur, Y.S., and Picciotto, M.R. (2013). Morphine dependence and withdrawal induced changes in cholinergic signaling. Pharmacol. Biochem. Behav. 109, 77-83.

Nguyen, T.L., Kwon, S.H., Hong, S.I., Ma, S.X., Jung, Y.H., Hwang, J.Y., Kim, H.C., Lee, S.Y., and Jang, C.G. (2014). Transient receptor potential vanilloid type 1 channel may modulate opioid reward. Neuropsychopharmacology 39, 2414-2422

Nunez, C., Martin, F., Foldes, A., Luisa Laorden, M., Kovacs, K.J., and Victoria Milanes, M. (2010). Induction of FosB/DeltaFosB in the brain stress system-related structures during morphine dependence and withdrawal. J. Neurochem. 114, 475-487.

Olmstead, M.C., and Franklin, K.B. (1997). The development of a conditioned place preference to morphine: effects of microinjections into various CNS sites. Behav. Neurosci. 111, 13241334.

Peters, J. and De Vries, T.J. (2012). Glutamate mechanisms underlying opiate memories. Cold Spring Harb. Perspect. Med. 2 a012088.

Pickel, V.M., Chan, J., Kash, T.L., Rodriguez, J.J., and MacKie, K. (2004). Compartment-specific localization of cannabinoid 1 (CB1) and mu-opioid receptors in rat nucleus accumbens. Neuroscience 127, 101-112.

Polissidis, A., Galanopoulos, A., Naxakis, G., Papahatjis, D., Papadopoulou-Daifoti, Z., and Antoniou, K. (2013). The cannabinoid CB1 receptor biphasically modulates motor activity and regulates dopamine and glutamate release region dependently. Int. J. Neuropsychopharmacol. 16, 393-403.

Pontieri, F.E., Tanda, G., and Di Chiara, G. (1995). Intravenous cocaine, morphine, and amphetamine preferentially increase extracellular dopamine in the "shell" as compared with the "core" of the rat nucleus accumbens. Proc. Natl. Acad. Sci. USA 92, 12304-12308.

Pu, L., Bao, G.B., Xu, N.J., Ma, L., and Pei, G. (2002). Hippocampal long-term potentiation is reduced by chronic opiate treatment and can be restored by re-exposure to opiates. J. Neurosci. 22, 19141921.

Quirk, G.J., and Mueller, D. (2008). Neural mechanisms of extinction learning and retrieval. Neuropsychopharmacology 33, 56-72.

Rashidy-Pour, A., Pahlevani, P., Vaziri, A., Shaigani, P., Zarepour, L., Vafaei, A.A. and Haghparast, A. (2013). Involvement of CB1 receptors in the ventral tegmental area in the potentiation of morphine rewarding properties in acquisition but not expression in the conditioned place preference model. Behav. Brain Res. 247, 259-267.

Razavi, Y., Karimi, S., Bani-Ardalan, M., and Haghparast, A. (2014). Chemical stimulation of the lateral hypothalamus potentiated the sensitization to morphine in rats: involvement of orexin-1 receptor in the ventral tegmental area. EXCLI J. 13, 1120-1130.

Rei, D., Mason, X., Seo, J., Graff, J., Rudenko, A., Wang, J., Rueda, R., Siegert, S., Cho, S., Canter, R.G., et al. (2015). Basolateral amygdala bidirectionally modulates stress-induced hippocampal learning and memory deficits through a p25/Cdk5-dependent pathway. Proc. Natl. Acad. Sci. USA 112, 7291-7296.

Rezayof, A., Zarrindast, M.R., Sahraei, H., and Haeri-Rohani, A.H. (2002). Involvement of dopamine D2 receptors of the centra amygdala on the acquisition and expression of morphine-induced place preference in rat. Pharmacol. Biochem. Behav. 74, 187197.

Rezayof, A., Nazari-Serenjeh, F., Zarrindast, M.R., Sepehri, H., and Delphi, L. (2007). Morphine-induced place preference: involvement of cholinergic receptors of the ventral tegmental area. Eur. J. Pharmacol. 562, 92-102.

Rezayof, A., Darbandi, N., and Zarrindast, M.R. (2008). Nicotinic acetylcholine receptors of the ventral tegmental area are involved in mediating morphine-state-dependent learning. Neurobiol. Learn. Mem. 90, 255-260.

Rezayof, A., Hosseini, S.S., and Zarrindast, M.R. (2009). Effects of morphine on rat behaviour in the elevated plus maze: the role of central amygdala dopamine receptors. Behav. Brain Res. 202, 171-178.

Richardson, K.A., and Aston-Jones, G. (2012). Lateral hypothalamic orexin/hypocretin neurons that project to ventral tegmental area are differentially activated with morphine preference. J. Neurosci. 32, 3809-3817.

Rosen, L.G., Zunder, J., Renard, J., Fu, J., Rushlow, W., and Laviolette, S.R. (2015). Opiate exposure state controls a D2CaMKIlalpha-dependent memory switch in the amygdalaprefrontal cortical circuit. Neuropsychopharmacology 41, 847-857.

Russo, S.J., Bolanos C.A., Theobald D.E., DeCarolis N.A., Renthal W., Kumar A., Winstanley C.A., Renthal N.E., Wiley M.D., Self D.W., et al. (2007). IRS2-Akt pathway in midbrain dopamine neurons regulates behavioral and cellular responses to opiates. Nat. Neurosci. 10, 93-99.

Sakurai, T., Amemiya A., Ishii M., Matsuzaki I., Chemelli R.M., Tanaka H., Williams S.C., Richardson J.A., Kozlowski G.P. Wilson S., et al. (1998). Orexins and orexin receptors: a family of hypothalamic neuropeptides and $G$ protein-coupled receptors that regulate feeding behavior. Cell 92, 573-585.

Schott, B.H., Sellner, D.B., Lauer, C.J., Habib, R., Frey, J.U., Guderian, S., Heinze, H.J., and Duzel, E. (2004). Activation of midbrain structures by associative novelty and the formation of explicit memory in humans. Learn. Mem. 11, 383-387.

Schug, S.A., Zech, D., Grond, S., Jung, H., Meuser, T., and Stobbe, B. (1992). A long-term survey of morphine in cancer pain patients J. Pain Symptom Manage. 7, 259-266.

Schultheiss, R., Schramm, J., and Neidhardt, J. (1992). Dose changes in long- and medium-term intrathecal morphine therapy of cancer pain. Neurosurgery 31, 664-669; discussion 669-670.

Schultz, W. (2002). Getting formal with dopamine and reward. Neuron 36, 241-263.

Sesack, S.R., and Carr, D.B. (2002). Physiol. Behav. 77, 513-517.

Stamatakis, A.M., Sparta, D.R., Jennings, J.H., McElligott, Z.A. Decot, H., and Stuber, G.D. (2014). Amygdala and bed nucleus of the stria terminalis circuitry: Implications for addiction-related behaviors. Neuropharmacology 76 (Pt B), 320-328.

Steidl, S., and Yeomans, J.S. (2009). M5 muscarinic receptor knockout mice show reduced morphine-induced locomotion but increased locomotion after cholinergic antagonism in the ventral tegmental area. J. Pharmacol. Exp. Ther. 328, 263-275.

Suto, N., Wise, R.A., and Vezina, P. (2011). Dorsal as well as ventral striatal lesions affect levels of intravenous cocaine and morphine self-administration in rats. Neurosci. Lett. 493, 29-32.

Szabo, B., Siemes, S., and Wallmichrath, I. (2002). Inhibition of GABAergic neurotransmission in the ventral tegmental area by cannabinoids. Eur. J. Neurosci. 15, 2057-2061.

Tan, K.R., Yvon, C., Turiault, M., Mirzabekov, J.J., Doehner, J., Labouebe, G., Deisseroth, K., Tye, K.M., and Luscher, C. (2012). GABA neurons of the VTA drive conditioned place aversion. Neuron 73, 1173-1183.

Tan, H., Rosen, L.G., Ng, G.A., Rushlow, W.J., and Laviolette, S.R. (2014). NMDA receptor blockade in the prelimbic cortex activates the mesolimbic system and dopamine-dependent opiate reward signaling. Psychopharmacology (Berl.). 231, 4669-4679.

Tanda, G., Pontieri, F.E., and Di Chiara, G. (1997). Cannabinoid and heroin activation of mesolimbic dopamine transmission by a common mu1 opioid receptor mechanism. Science 276, 2048- 
2050.

Taylor, A.M., Castonguay, A., Ghogha, A., Vayssiere, P., Pradhan, A.A., Xue, L., Mehrabani, S., Wu, J., Levitt, P., Olmstead, M.C., et al. (2015). Neuroimmune regulation of GABAergic neurons within the ventral tegmental area during withdrawal from chronic Morphine. Neuropsychopharmacology 41, 949-959.

Trujillo, K.A., and Akil, H. (1991). Inhibition of morphine tolerance and dependence by the NMDA receptor antagonist MK-801. Science 251, 85-87.

van Zessen, R., Phillips, J.L., Budygin, E.A., and Stuber, G.D. (2012). Activation of VTA GABA neurons disrupts reward consumption. Neuron 73, 1184-1194.

Ventura, R., Alcaro, A., and Puglisi-Allegra, S. (2005). Prefrontal cortical norepinephrine release is critical for morphine-induced reward, reinstatement and dopamine release in the nucleus accumbens. Cereb. Cortex 15, 1877-1886.

Watanabe, T., Nakagawa, T., Yamamoto, R., Maeda, A., Minami, M., and Satoh, M. (2003). Involvement of noradrenergic system within the central nucleus of the amygdala in naloxoneprecipitated morphine withdrawal-induced conditioned place aversion in rats. Psychopharmacology (Berl.). 170, 80-88.

Yu, G., Yan, H., and Gong, Z.H. (2012). Differential effects of acute and repeated morphine treatment on kappa-opioid receptor mRNA levels in mesocorticolimbic system. Pharmacol. Rep. 64
445-448.

Zarrindast, M.R., Rezayof, A., Sahraei, H., Haeri-Rohani, A., and Rassouli, Y. (2003). Involvement of dopamine D1 receptors of the central amygdala on the acquisition and expression of morphine-induced place preference in rat. Brain Res. 965, 212221.

Zarrindast, M.R., Nouri, M., and Ahmadi, S. (2007). Cannabinoid CB1 receptors of the dorsal hippocampus are important for induction of conditioned place preference (CPP). but do not change morphine CPP. Brain Res. 1163, 130-137.

Zarrindast, M.R., Eslahi, N., Rezayof, A., Rostami, P., and Zahmatkesh, M. (2013). Modulation of ventral tegmental area dopamine receptors inhibit nicotine-induced anxiogenic-like behavior in the central amygdala. Prog. Neuropsychopharmacol. Biol. Psychiatry 41, 11-17.

Ziolkowska, B., Gieryk, A., Solecki, W., and Przewlocki, R. (2015). Temporal and anatomic patterns of immediate-early gene expression in the forebrain of $\mathrm{C} 57 \mathrm{BL} / 6$ and DBA/2 mice after morphine administration. Neuroscience 284, 107-124.

Zhou, Y., Bendor, J., Hofmann, L., Randesi, M., Ho, A., and Kreek, M.J. (2006). Mu opioid receptor and orexin/hypocretin mRNA levels in the lateral hypothalamus and striatum are enhanced by morphine withdrawal. J. Endocrinol. 191, 137-145. 